\title{
Register autorum ad Vol. 1 et 2
}

$\mathrm{B}$ = Buchbesprechung - Book Review - Livre nouveau V = Varia

Anderson, J. E., 1: 5, 127 (B)

Bergler, R., 2: 149 Berner, P., und Hoff, H., 2: 165 Bossio, V., v. Pringle, M. L. K. Burger, M.,2: 119 (B)

Dailey, C. A., 2: 11 David, H. P., 2: 119 (B)

Eyferth, K., 2: 102

Gerfeldt, E., /; 19; 2: 120 (B) Gerfeldt, E., und H., 2: 117 (V) Gerfeldt, H., v. Gerfeldt, E. Hagen, W., Thomae, H., Mansfeldt, E., und Mathey, F. J., 2: 118 (B) Harmsen, H., 2: 1 Harris, D. B., 1: 250 (B) Haupt, K., 2: 35 Havighurst, R.J.,2: 25 Hoff, H., v. Berner, P.

Jones, H. E., 1: 43, 93

Karsten, A., 2: 87, 118 (V)

Lehr, U., und Thomae, H., /: 100 Lehr, U., 2: 101

Mansfeldt, E., 1: 246 (V) Mansfeldt, E., v. Hagen, W. Mathey, F. J., v. Hagen, W. Mathey, R., 1: 250 (B) Moore, T. W., 2: 65

O’Connor, C. M., v. Wolstenholme,

G. E. W. Olum, V., 1: 191

Prang, H., 1: 171

Pringle, M. L. K., and Bossio, V., 1: 65,

142 Pringle, M. L. K., 1: 249 (B)

Riegel, K. F., 1: 52, 111, 204; 2: 213

Stott, D. H., 2: 125

Thomae, H., 1: 128 (B), 247 (B),

252 (B) Thomae, H., v. Hagen, W. Thomae, H., v. Lehr, U.

Vischer, A. L., /: 129

Wolstenholme, G. E. W., and O’Connor, C. M., 1: 249 (B) 